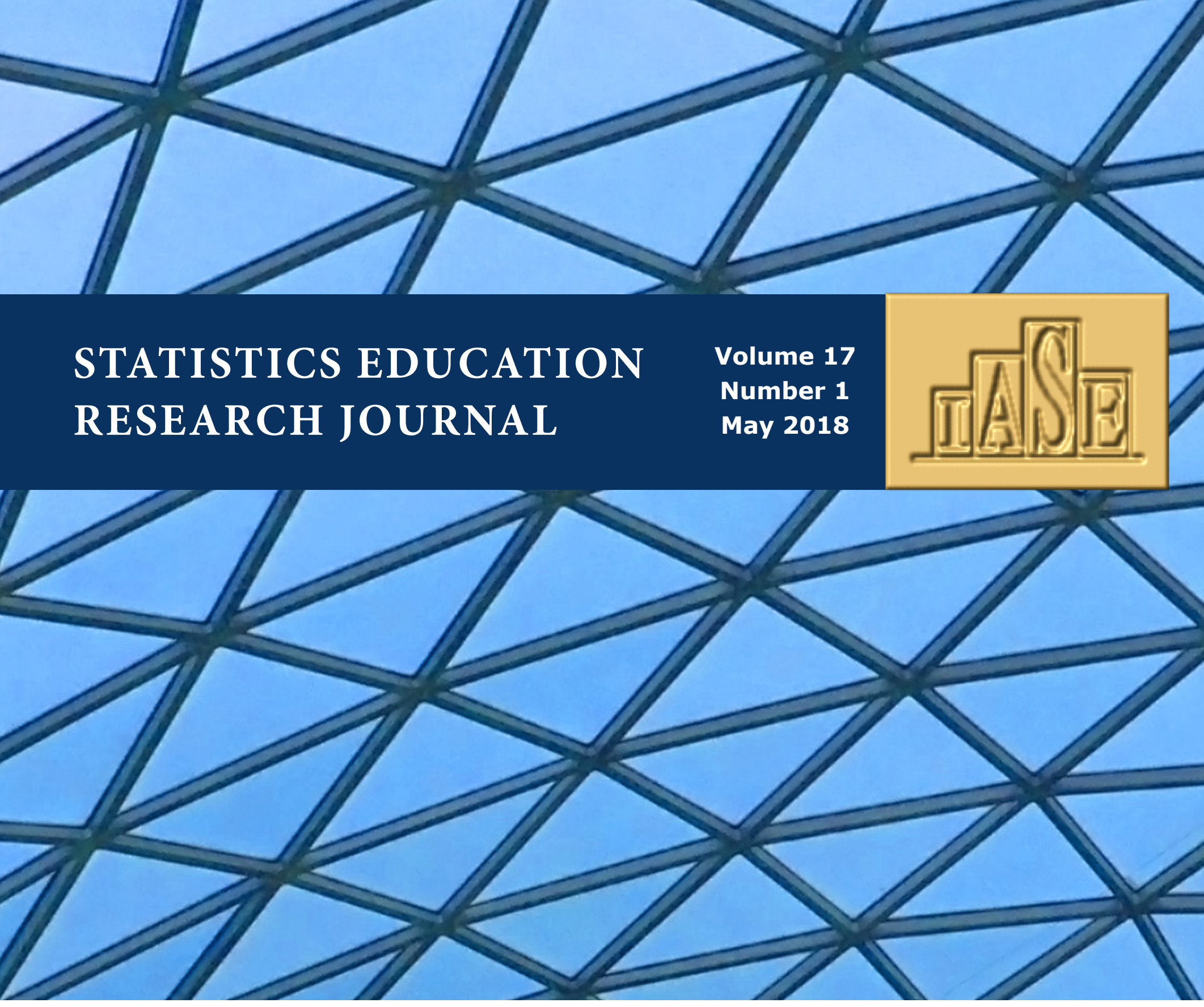

\section{EDITORS}

Manfred Borovenik

Jennifer Kaplan

Maxine Pfannkuch

\section{ASSOCIATE EDITORS}

Egan Chernoff Stefania Mignani

Sue Finch Michele Millar

Randall Groth Jennifer Noll

Leigh Harell-Williams M. Gabriella Ottaviani

Aisling Leavy Susan Peters

Hollylynne Stohl Lee Dave Pratt

Alejandra Sorto

\title{
ASSISTANT EDITOR
}

Beth Chance 


\section{STATISTICS EDUCATION RESEARCH JOURNAL}

The Statistics Education Research Journal (SERJ) is a peer-reviewed electronic journal of the International Association for Statistical Education (IASE) and the International Statistical Institute (ISI). SERJ is published twice a year and is open access.

SERJ aims to advance research-based knowledge that can help to improve the teaching, learning, and understanding of statistics or probability at all educational levels and in both formal (classroombased) and informal (out-of-classroom) contexts. Such research may examine, for example, cognitive, motivational, attitudinal, curricular, teaching-related, technology-related, organizational, or societal factors and processes that are related to the development and understanding of stochastic knowledge. In addition, research may focus on how people use or apply statistical and probabilistic information and ideas, broadly viewed.

The Journal encourages the submission of quality papers related to the above goals, such as reports of original research (both quantitative and qualitative), integrative and critical reviews of research literature, analyses of research-based theoretical and methodological models, and other types of papers described in full in the Guidelines for Authors. All papers are reviewed internally by an Associate Editor or Editor, and are blind-reviewed by at least two external referees. Contributions in English are recommended. Contributions in French and Spanish will also be considered. A submitted paper must not have been published before or be under consideration for publication elsewhere.

Further information and guidelines for authors are available at:

http://iase-web.org/Publications.php?p=SERJ

\section{Submissions}

Manuscripts must be submitted by email, as an attached Word document, to co-editor Jennifer Kaplan $<$ jkaplan@uga.edu>. Submitted manuscripts should be produced using the Template file and in accordance with details in the Guidelines for Authors on the Journal's Web page:

http://iase-web.org/Publications.php?p=SERJ

(C) International Association for Statistical Education (IASE/ISI), May 2018

Publication: IASE/ISI, The Hague, The Netherlands

Technical Production: California Polytechnic State University, San Luis Obispo, California, United States of America

ISSN: 1570-1824

International Association for Statistical Education (IASE) - an association of the International Statistical Institute (ISI)

President: Gail Burrill (USA)

President-Elect: Joachim Engel (Germany)

Past- President: Andrej Blejec (Slovenia)

Vice-Presidents: Ayse Bilgin (Australia), Stepanie Budgett (New Zealand), Pedro Campos (Portugal), Thi Thanh Loan le (Vietnam), Teresita Terán (Argentina) 


\section{SERJ EDITORIAL BOARD}

Editors

Manfred Borovcnik, Department of Statistics Alpen-Adria, Universität Klagenfurt, Austria. Email: manfred.borovcnik@aau.at

Jennifer Kaplan, Department of Statistics, University of Georgia, 401 Brooks Hall, 310 Herty Drive, Athens, Georgia 30601, USA. Email: jkaplan@uga.edu

Maxine Pfannkuch, Department of Statistics, The University of Auckland, Private Bag 92019, Auckland, New Zealand. Email: m.pfannkuch@auckland.ac.nz

\section{Assistant Editor}

Beth Chance, Department of Statistics, California Polytechnic State University, San Luis Obispo, California, 93407, USA. Email: bchance@calpoly.edu

\section{Associate Editors}

Egan Chernoff, College of Education, University of Saskatchewan, Saskatoon SK S7N0X1, Canada. Email: egan.chernoff@usask.ca

Sue Finch, Statistical Consulting Centre, The University of Melbourne, Australia. Email: sfinch@unimelb.edu.au

Randall E. Groth, Department of Education Specialties, Salisbury University, Salisbury, MD 21801, USA. Email: regroth@salisbury.edu

Leigh Harrell-Williams, Department of Counseling, Educational Psychology \& Research, University of Memphis, Memphis, TN 38152, USA. Email: 1mwllm14@memphis.edu

Aisling Leavy, Department of Language, Literacy and Mathematics Education, Mary Immaculate College, University of Limerick, Limerick, Ireland. Email: aisling.leavy@mic.ul.ie

Hollylynne Stohl Lee, Department of Science, Technology, Engineering, and Mathematics Education, North Carolina State University, Raleigh, NC 27695, USA. Email: hollylynne@ncsu.edu

Stefania Mignani, Dipartimento di Scienze Statistiche, Università di Bologna, Italy. Email: stefania.mignani@unibo.it

Michele Millar, Department of Mathematics and Computer Science, Mount Saint Vincent University, Halifax, Nova Scotia, Canada. Email: michele.millar@msvu.ca

Jennifer Noll, Fariborz Maseeh Department of Mathematics and Statistics, Portland State University, Portland, Oregon, USA. Email: noll@pdx.edu

Maria Gabriella Ottaviani, Dipartimento di Statistica Probabilitá e Statistiche Applicate, Universitá degli Studi di Roma "La Sapienza", Rome, Italy. Email: Mariagabriella.ottaviani@uniroma1.it

Susan Peters, Department of Middle and Secondary Education, College of Education and Human Development, University of Louisville, Louisville, KY, USA. Email: s.peters@louisville.edu

Dave Pratt, Institute of Education, University of London, London WC1H 0AL. Email: d.pratt@ioe.ac.uk

M. Alejandra Sorto, Department of Mathematics, Texas State University, San Marcos, TX 78666, USA.Email: sorto@txstate.edu 


\section{TABLE OF CONTENTS}

Michelle Forsythe

Sampling in the Wild: How Attention to Variation Supports Middle School Students' Sampling Practice

Daniel Frischemeier and Rolf Biehler

Preservice Teachers Comparing Groups with Tinkerplots-An Exploratory Laboratory Study

Maryann Huey, Joe Champion, Stephanie Casey, and Nicholas Wasserman Secondary Mathematics Teachers' Planned Approaches for Teaching Standard Deviation

Jennifer Kaplan, Alexander Lyford, and Jeremy Jennings Effects of Question Stem on Student Descriptions of Histograms

Laura Hildreth, Jim Robison-Cox, and Jade Schmidt Comparing Student Success and Understanding in Introductory Statistics under Consensus and Simulation-Based Curricula

Perpetua Lynne Nielsen, Nathan William Bean, and Ross Allen Andrew Larsen The Impact of a Flipped Classroom Model of Learning on a Large Undergraduate Statistics Class

Amy E. Wagler and Lawrence M. Lesser Evaluation of Theoretical and Empircal Characteristics of the Communication, Lanuguage, and Statistics Survey (CLASS)

Conferences 


\section{EDITORIAL}

Welcome to the first issue of SERJ for 2018. Submission of regular papers to SERJ is growing. During this period of growth, I would like to thank all the SERJ Associate Editors and reviewers for their continued support, many hours of voluntary service, and their commitment to assisting authors to improve their papers and to maintain high standards. Other people involved in the production of SERJ are Jennifer Kaplan, who is now the Editor for the Regular Papers, Manfred Borovcnik, Editor for the Special Issues, and Beth Chance, the Assistant Editor. The constant voluntary work of all these people ensures that an aim of SERJ, to advance research-based knowledge in statistics education, is met. Reflecting this growth, the current system for delivering SERJ is under review by the IASE (International Association of Statistical Education).

There are seven articles in this issue. One article attends to young students' emergent understandings about sampling within an ecological context. Two articles focus on preservice or in-service teachers' understanding of statistics. Four articles report on introductory students' encounters with statistics focusing on performance on specific assessment items, different curricula, and different learning strategies to meet the needs of culturally and linguistically diverse students.

Michelle Forsythe describes how sixth-grade students doing an investigation in a local creek started to understand how to collect data using ecological sampling decisions and practices. By drawing students' attention to variation, using a student-driven learning strategy, she scaffolded students to consider doing multiple observations, recording presence and absence, and sampling location. Pre- and post-tests, student interviews, artifacts, and video recordings were used to trace the students' changing perspectives about sampling. Her study is not only a reminder that statistics is a cross-curricular discipline but also that other disciplines can provide valuable insights into students' statistical reasoning.

Daniel Frischemeier and Rolf Biehler report on a study in which they assessed eight preservice teachers' reasoning when using TinkerPlots ${ }^{\mathrm{TM}}$ to compare two groups. Using two frameworks, one to rate performance and one to rate software skills, they concluded that TinkerPlots and the design of their course were supporting the development of these preservice teachers' reasoning. However, extra learning opportunities were required to improve their use of more reasoning elements. From a research perspective, their study exemplifies how to carefully craft frameworks based on the literature and how to explicate and conduct an analysis procedure for coding qualitative responses.

Maryann Huey, Joe Champion, Stephanie Casey, and Nicholas Wasserman conducted an exploratory study to understand how 16 preservice and in-service teachers from four institutions would devise lesson plans to teach standard deviation. They analysed the lesson plans using a six-stage productive learning activities trajectory in order to characterise them and to determine factors influencing those characterizations. This study offers some insights into teachers' conceptions and pedagogical practice regarding standard deviation and has implications for teacher education.

Jennifer Kaplan, Alexander Lyford, and Jeremy Jennings focus on assessment of introductory statistics students' reasoning and how the phrasing of questions and different scenarios leads to systematic differences in how students describe histograms. Their research offers some new perspectives on determining the validity and reliability of assessment items.

Laura Hildreth, Jim Robison-Cox, and Jade Schmidt contribute to the debate on whether simulationbased curricula improve introductory statistics students' understanding compared to traditional curricular. In their comparison of student success rates and understanding of six key statistical concepts, they add to a growing body of evidence that while success rates may be similar across the two curricula, understanding is similar to or better in several key statistical conceptual areas for simulation-based curricula.

Statistics Education Research Journal, 17(1), 6-7, http://iase-web.org/Publications.php?p=SERJ

(C) International Association for Statistical Education (IASE/ISI), May, 2018 
Lynne Nielsen, Nathan Bean, and Ross Larsen compare a flipped classroom model of learning with a traditional model by examining the impact on 365 introductory statistics students' performance and satisfaction. Using eight variables as controls they determined through a number of analyses that their particular flipped classroom model had the potential to improve students' performance and attitude towards introductory statistics courses. With flipped classrooms becoming more prominent as a learning strategy, it is essential that such changes in the learning landscape have solid research evidence underpinning their claimed effectiveness.

Amy Wagler and Lawrence Lesser focus on improving instruction with culturally and linguistically diverse introductory statistics students by attending to the interaction between language and learning of statistical concepts. Over a number of years they have assiduously developed, trialled, evaluated, and refined a survey instrument, CLASS (Communication, Language and Statistics Survey), in order to assist educators better address the learning preferences and needs of their classes. In this paper they present an evaluation of their third version of CLASS using mixed methods, which led to the production of the fourth version.

MAXINE PFANNKUCH 